\title{
desenvolvimento QUESTAOO
}

\section{Economia Circular \\ Estudo de Casos Múltiplos em Usinas de Reciclagem no Manejo de Resíduos da Construção Civil}

http://dx.doi.org/10.21527/2237-6453.2019.49.136-157

Recebido em: 13/8/2018

Aceito em: $11 / 6 / 2019$

\section{João Alexandre Paschoalin Filho, ${ }^{1}$ Sueli Aparecida Frasson, ${ }^{2}$ Diego de Melo Conti ${ }^{3}$}

\begin{abstract}
RESUMO
Com a função de reciclar os Resíduos da Construção Civil (RCC), as Usinas de Reciclagem de Entulho (URE) reduzem o impacto do setor no meio ambiente. Assim, é apresentada neste trabalho uma discussão acerca do papel das UREs na promoção da Economia Circular no gerenciamento de resíduos da construção civil. Para tal, foi utilizada metodologia de estudos de casos múltiplos em sete UREs situadas na região de São Paulo, bem como entrevistas com gestores das UREs, com o presidente da Associação Brasileira para Reciclagem de Resíduos de Construção Civil e Demolição, além de engenheiros com experiência em obras civis. Conclui-se que as UREs possuem potencial na promoção da Economia Circular, no entanto apresentam limitações, entre as quais destacam-se a falta de programas de qualidade dos agregados reciclados, utilização de métodos pouco eficientes de triagem, baixa qualificação de mão de obra, falta de esclarecimento ao mercado e ausência leis que incentivem uso dos resíduos em obras.
\end{abstract}

Palavras-chave: Usinas de Reciclagem de Entulho. Resíduos de construção civil. Sustentabilidade.

\section{CIRCULAR ECONOMY: MULTICASE STUDY ABOUT RECYCLING PLANTS IN} WASTE MANAGEMENT OF CIVIL CONSTRUCTION SOLID WASTES

\begin{abstract}
With the purpose of recycling construction and demolition wastes (CDW), CDW Recycling Plants (CDWRP) reduce the impact of the sector on the environment. This paper presents a discussion about the role of CDWRP in the promotion of the Circular Economy in the management of construction waste. A multicase study was used in seven CDWRPs located in the region of São Paulo, as well as interviews with CDWRPs managers, the President of the Brazilian Association for the Recycling of Civil Construction and Demolition Waste, as well as engineers with experience in civil works It is concluded that CDWRPs have potential in the promotion of the Circular Economy, however, they present limitations; the lack of quality programs for recycled aggregates, the use of inefficient screening methods, low labor qualification, lack of clarification to the market, and lack of laws that encourage the use of waste in construction.
\end{abstract}

Keywords: Construction waste recycling plants. Construction and demolition wastes. Sustainability.

\footnotetext{
${ }^{1}$ Doutor em Engenharia Agrícola pela Universidade Estadual de Campinas (Unicamp). Professor do Programa de Mestrado em Gestão Ambiental e Sustentabilidade da Universidade Nove de Julho (Uninove). jalexandre@uni9.pro.br

${ }^{2}$ Graduada em Engenharia Civil pela Universidade Nove de Julho (Uninove). sueli_frasson@yahoo.com

${ }^{3}$ Doutor em Administração pela Pontifícia Universidade Católica de São Paulo (PUC-SP). Professor do Programa de Mestrado em Cidades Inteligentes e Sustentáveis da Universidade Nove de Julho (Uninove). diegoconti@uol.com.br
} 
A indústria da construção civil desempenha um importante papel no desenvolvimento das cidades. Segundo a Câmara Brasileira da Indústria da Construção - CBIC (2016), trata-se de um setor que influencia diretamente a economia de um país, gerando empregos diretos e indiretos. Na visão de Karpinski et al. (2008), este setor é o principal responsável por garantir a infraestrutura necessária para o desenvolvimento do Brasil.

John (2000) e Dias (2004), contudo, ressaltam que a construção civil consiste na atividade econômica que mais consome recursos naturais, utilizando em torno de $50 \%$ de tudo que é extraído mundialmente. Segundo John (2000), somente na produção de concreto e argamassa são utilizadas cerca de 220 milhões de ton./ano de agregados naturais. Além disso, Esa, Halog e Rigamonti (2017a) destacam que 40\% de todo resíduo produzido pelas atividades industriais advêm da construção civil.

Ulsen et al. (2010) estimam que os resíduos de construção possam constituir cerca de $50 \%$ dos resíduos sólidos de algumas municipalidades brasileiras. Azevedo e Kiperstok (2006) citam que, na cidade de Salvador, o volume de RCC constitui em torno de $45 \%$ do total gerado diariamente de RSU; enquanto em São Paulo e Rio de Janeiro essa participação decai para 21\% (GOMES et al., 2008).

Na União Europeia, os RCC constituem cerca de $22 \%$ do volume total de resíduos sólidos urbanos (BARROS; JORGE, 2008). Tam, Kotrayothar e Loo (2009) comentam que $68 \%$ dos resíduos sólidos produzidos na Austrália são oriundos de atividades da construção civil. Na Índia, de acordo com Esa, Halog e Rigamonti (2017a), são geradas anualmente 14,5 milhões de toneladas de RCC, enquanto na Malásia este valor situa-se em 20 milhões. Por este motivo, a reciclagem de entulho tem sido tema de estudos nacionais e internacionais no intuito de possibilitar a valoração dos resíduos gerados nas obras e mitigar os impactos ambientais causados (ARIF; BENDI; TOMA-SABBAGH 2012).

Para Paschoalin Filho, Duarte e Faria (2016), a utilização de práticas gerenciais que visem à sintonia das operações do setor da construção civil com a sustentabilidade consiste em um importante paradigma a ser discutido pelo meio técnico, uma vez que proporciona a redução do impacto ambiental causado pela sua cadeia produtiva, dos custos incorridos e colabora na solidificação de uma boa imagem das empresas envolvidas junto ao mercado consumidor e stakeholders.

Para reduzir os impactos ambientais gerados pelos RCC, Schneider e Philippi Jr. (2004) apontam a reciclagem destes como uma possível solução. Segundo John (2000), a reciclagem contribui na produção de materiais que serão utilizados em novas construções, reduzindo o custo das novas obras, além da necessidade de aquisição de matérias primas.

No contexto da reciclagem dos RCC destaca-se a atuação das Usinas de Reciclagem de Entulho (UREs), uma vez que estas não consistem apenas em uma forma de destinação final dos RCC, mas sim em um ponto de reinserção destes na cadeia produtiva da construção civil. De acordo com pesquisa setorial realizada pela Associação Brasileira para Reciclagem de Resíduos da Construção Civil e Demolição (Abrecon) para o período de 2015 a 2016 foram contabilizadas 310 usinas instaladas em diferentes regiões do país, o que demonstra que, em um período de 6 anos, de 2009 a 2015, este crescimento 
ultrapassou 43 novas instalações por ano, sendo 10\% pertencentes ao setor público, $83 \%$ ao setor privado e $7 \%$ misto público/privado, o que revela a grande modificação que o setor vem apresentando (ABRECON, 2016).

Deve-se destacar que grande parte dos impactos causados pelo setor da construção civil, principalmente em relação aos resíduos gerados, advém do fato de uma significativa parcela das construtoras ainda trabalhar sua cadeia produtiva de forma linear, tal como já demonstrado por autores como Leitão (2015) e Leal (2015). De acordo com os autores, uma importante ferramenta para inserção da preocupação ambiental no setor da construção civil é a utilização dos princípios de Economia Circular (EC) em suas atividades. Para Esa, Halog e Rigamonti (2017a), a fase executiva das obras contribui com as maiores quantidades de resíduos quando esta não é eficientemente gerenciada. Segundo os autores, o grande volume de resíduos ocorre pela forma linear como as obras são geridas, ou seja, sempre baseadas na prática da seguinte ideia: "extrair - produzir - consumir - descartar".

O conceito de Economia Circular (EC) é baseado em um modelo econômico em que os recursos são utilizados de forma racionalizada e maximizada, explorando a eficiência dos processos, buscando sempre a reutilização e poupando o uso de recursos naturais. Esta consiste em um ciclo fechado de desenvolvimento, que atua de forma contínua e não linear (ELLEN..., 2017; MURRAY; SKENE; HAYNES 2017).

Diante deste contexto, apresenta-se a seguinte questão que norteou esta pesquisa: Como as UREs podem contribuir na promoção da Economia Circular no setor da construção civil?

Diante da problemática apresentada, portanto, justifica-se esta pesquisa. Assim, o objetivo geral deste trabalho consiste em fomentar a discussão acerca do papel das Usinas de Reciclagem de Entulho na promoção da Economia Circular na construção civil, de forma que estas venham a contribuir de forma mais efetiva na inserção da variável ambiental na construção civil. Os objetivos específicos desta pesquisa foram: caracterizar as UREs em estudos; verificar a opinião de engenheiros, gestores das UREs e do presidente da Abrecon acerca do potencial de uso dos agregados reciclados nas obras particulares e públicas, políticas de incentivo a utilização destes, bem como vantagens financeiras de sua utilização e perspectivas de uso.

Arif, Bendi e Toma-Sabbagh (2012) ressaltam a importância de estudos acerca dos impactos causados pelas atividades construtivas. Os autores incentivam os pesquisadores para que intensifiquem estudos de novas ferramentas de gerenciamento dos resíduos gerados nas obras, na intenção de se mitigar os impactos causados e promover a inserção da variável ambiental na indústria da construção civil.

Segundo Esa, Halog e Rigamonti (2017a) e Adams et al. (2017), existe uma distância entre a pesquisa acadêmica e a adoção dos princípios da Economia Circular na construção civil. Esa, Halog e Rigamonti (2017b) explicam que há uma grande necessidade de integrar a Economia Circular à indústria da construção civil, de forma a garantir a redução dos resíduos gerados pelo setor e criar um futuro mais sustentável. 


\section{REVISÃO DE LITERATURA}

\section{Usinas de Reciclagem de Entulho no Manejo dos RCC}

A reciclagem de RCC já ocorre desde os anos 1920 (LEVY; HELENE, 2002). De acordo com os autores, por volta de 1928 foram iniciadas pesquisas no intuito de se avaliar tecnicamente a dosagem de concreto utilizando-se resíduos de construção, destacando-se que a reutilização de RCC mais significativa foi registrada após a Segunda Guerra Mundial, quando estes foram utilizados na reconstrução das cidades europeias no período pós-guerra.

No Brasil, Bodi, Brito Filho e Almeida (1995) registram que no ano de 1984 foi realizada a pavimentação da primeira via de tráfego na cidade de São Paulo com aplicação de agregados reciclados nas camadas de reforço do subleito, bem como na sub-base, garantindo qualidade satisfatória no desempenho da via.

Segundo Melo (2011), o primeiro registro de elaboração de um Plano Municipal de Gestão de Resíduos da Construção Civil ocorreu no ano de 1993 na cidade de Belo Horizonte, no intuito de se tratar os resíduos e evitar a sua deposição final em locais clandestinos. Posteriormente, em 1995, foi inaugurada a primeira central de reciclagem da capital mineira, com uma segunda usina inaugurada no ano seguinte (1996) no bairro da Pampulha.

Em Ribeirão Preto, no ano de 1996, foi inaugurada a primeira usina do interior do Estado de São Paulo e, posteriormente, no mesmo ano, mais uma usina foi inaugurada em São José dos Campos/SP, no entanto esta última foi fechada dois anos após sua inauguração (CUNHA, 2007).

O manejo sustentável dos RCC tem merecido atenção de pesquisadores e da indústria da construção civil, que têm buscado formas de reduzir sua geração e viabilizar a sua reutilização e reciclagem. O uso dos RCC em obras pode ocorrer sob várias formas, tais como: agregados para concreto não estrutural, na produção de argamassa, blocos e tijolos não estruturais, na pavimentação de estradas, em obras de drenagem, estabilização de encostas, recuperação topográfica, entre outras possibilidades (LU; YUAN, 2011; YUAN, 2012).

Segundo Paschoalin Filho, Duarte e Faria (2016) e Esa, Halog e Rigamonti (2017b), uma importante ferramenta de gerenciamento sustentável de RCC consiste no modelo da pirâmide da hierarquia de gestão de resíduos sólidos, sendo esta recomendada em legislações nacionais e internacionais, tais como: a Política Nacional dos Resíduos Sólidos (PNRS) do Brasil (Lei 12.305/2010); a Diretiva 2008/98/CE, relativa aos resíduos da União Europeia, e a Lei de Recuperação e Conservação de Recursos (Ecra) da Agência de Proteção Ambiental (EPA) dos Estados Unidos (HWANG; YEO, 2011; INGLEZAKIS; ZORPAS, 2011).

De uma forma geral, a reciclagem dos resíduos de construção civil traz inúmeras vantagens técnicas, econômicas e ambientais, as quais foram estudadas por diversos pesquisadores (HWANG; YEO, 2011; ARIF; BENDI; TOMA-SABBAGH 2012; OYEDETE et al., 2013; PASCHOALIN FILHO et al., 2013). Conforme Souza, Segantini e Pereira (2008), a reciclagem dos RCC pode ser considerada uma alternativa ligada ao conceito de sustentabilidade, embutindo valor econômico, ambiental e social em materiais que 
seriam descartados. Evangelista, Costa e Zanta (2010) comentam que, desde que devidamente reciclado, o resíduo de construção civil pode apresentar propriedades para sua utilização como material de construção, no entanto, segundo Cunha (2007), o fato do agregado reciclado apresentar uma aparência bem graduada e limpa não assegura a qualidade do processo de reciclagem. Vários fatores podem interferir neste aspecto, desde a criação da usina até a estocagem final do produto reciclado.

Manfrenato, Esguícero e Martins (2008) apontam as Usinas de Reciclagem de Entulho (UREs) como uma alternativa para a reciclagem dos RCC e comentam que em diversos municípios já existem usinas produzindo agregados reciclados. Isso possibilitaria a resolução de um dos maiores desafios para o meio ambiente, criando alternativas para o reaproveitamento de materiais (SMOL et al., 2015). Melo, Ferreira e Costa (2013) destacam que as UREs são definidas como áreas industriais equipadas para o processamento de entulho em dois produtos finais distintos: agregado de resíduo de concreto (ARC) e agregado de resíduo misto (ARM). De acordo com Cunha (2007), o entulho, após triagem inicial, ao passar pelo processo de reciclagem, é britado e peneirado, resultando em agregados reciclados e peneirados.

Além do aspecto ambiental, a utilização de agregados reciclados também apresenta vantagens financeiras para as obras. Stevenato (2005) e Miranda, Ângulo e Careli (2009) observaram que os preços de comercialização de agregados reciclados são 40,5\% menores que agregados naturais de características semelhantes e para a mesma finalidade, no entanto Evangelista, Costa e Zanta (2010) ressaltam que a utilização de resíduos reciclados ainda não é prática difundida no Brasil.

John, Ângulo e Kahn (2006) destacam que, apesar de diversas normas técnicas nacionais e internacionais regulamentarem a utilização de agregados reciclados nas obras, existem várias especificidades que ainda dificultam sua utilização. Os autores ainda observam que o processo de inspeção das caçambas de RCC que chegam às UREs no Brasil é de baixa eficiência, sendo efetuado, predominantemente, apenas por meios visuais e manuais.

Para Paschoalin Filho, Duarte e Faria (2016), mesmo com as dificuldades apresentadas, os resíduos reciclados ainda possuem um grande potencial de inserção na construção civil, com sua utilização sendo destacada em sistemas de certificação ambiental de edifícios e em percentuais obrigatórios a ser empregados em obras públicas, tal como o estipulado pelo Plano de Gerenciamento Integrado de Resíduos Sólidos da cidade de São Paulo.

Na visão de Evangelista, Costa e Zanta (2010), a utilização dos agregados reciclados será impulsionada pelos seguintes fatores: indisponibilidade de aterros para deposição final, aceitação gradual do mercado consumidor, políticas públicas de incentivo à utilização e produção dos agregados reciclados, esgotamento das jazidas de materiais naturais, bem como exigências ambientais e de uma economia sã.

\section{Economia Circular na Construção Civil}

Segundo a Ellen MacArthur Foundation (2017), o conceito de Economia Circular (EC) tem origens profundas e não está ligada a uma data ou único autor, porém sua atuação sobre os processos, tanto econômico, quanto industrial, tomou força na década 
de 70 pela atuação de um grupo de acadêmicos, líderes e empresas. Geissdoerfer et al. (2017) reforçam que o conceito de EC ganhou impulso já no final da década de 70 . A Economia Circular consiste em um ciclo de desenvolvimento que atua de forma contínua e entre suas ações estão a otimização da produção de recursos e minimização de riscos sistêmicos (ELLEN..., 2017).

Murray, Skene e Haynes (2017) argumentam que a Economia Circular é a tentativa de integrar os princípios de sustentabilidade e de bem-estar ambiental nas atividades econômicas. Do mesmo modo, Ghisellini, Cialani e Ulgiati (2016) destacam que a EC estabelece um novo modelo de negócios, o qual proporciona condições para o desenvolvimento sustentável e a criação de uma sociedade mais harmoniosa.

A EC é fundamentada em três princípios voltados para desafios que se relacionam em recursos e sistemas, sendo estes: i) Preservar e aumentar o capital controlando estoques finitos e equilibrando os fluxos de recursos renováveis; ii) Otimizar a produção de recursos fazendo circular produtos, componentes e materiais no mais alto nível de utilidades o tempo todo, tanto no ciclo técnico quanto biológico; iii) Fomentar a eficácia dos sistemas, revelando as externalidades negativas e excluindo-as dos projetos (ELLEN..., 2017).

Segundo a Ellen MacArthur Foundation (2017) em seu relatório "Towards the Circular Economy: Economic and Business Rationale for an Accelerated Transition", a Economia Circular pode ser definida como um modelo que reinsere o resíduo no ciclo econômico e que envolve mudanças nas empresas e nos processos. Ghisellini, Cialani e Ulgiati (2016) ressaltam que a EC não é apenas um caminho para recuperação de materiais ou de energia, mas sim a proposta de um novo modelo de vida e econômico.

Nos últimos anos a EC tem sido tema de pesquisas acadêmicas no objetivo de se buscar uma ligação entre seu conceito e a prática empresarial. Para Leal (2015) existe certa desconfiança do setor empresarial em relação à Economia Circular, uma vez que a mudança envolve reestruturação e investimentos.

Sauvé, Bernard e Sloan (2016) ressaltam que o principal objetivo da Economia Circular é desconstruir a ideia de prosperidade atrelada ao consumo de recursos, sendo possível a criação de um processo de desenvolvimento que não dependa da extração de matérias-primas do meio natural. Assim, os autores propõem um sistema em que a reutilização e a reciclagem de materiais forneçam substitutos para o uso de matéria-prima virgem.

Segundo Esa, Halog e Rigamonti (2017a), diversos autores concordam que o setor da construção civil deve promover uma reflexão em relação à forma como está estruturada sua cadeia produtiva, procurando transformar o atual sistema linear em circular, de forma a poder atingir o desenvolvimento ambientalmente sustentável em suas atividades.

Geissdoerfer et al. (2017) reforçam que a Economia Circular possibilita a criação de uma economia restauradora e regenerativa, na qual a entrada de recursos e a saída de resíduos e emissões são minimizadas pela criação de um ciclo econômico fechado. Para Preston (2012), a Economia Circular consiste em um conceito baseado na redução do consumo de matérias-primas naturais. Segundo o autor, a Economia Circular é alinhada com a sustentabilidade, nas esferas ambiental, social e econômica. Da mesma 
forma, Ghisellini, Cialani e Ulgiati (2016) relatam que a Economia Circular concilia os elementos do desenvolvimento sustentável, principalmente porque fundamenta-se a partir de questões ambientais.

Dessa forma, a Economia Circular figura como uma ferramenta que pode ser utilizada para incrementar a economia linear a uma abordagem circular, por meio da maximização da utilização dos recursos. Na visão de Esa, Halog e Rigamonti (2017a), a Economia Circular não se baseia somente nos princípios da filosofia 3R, ou seja, Reduzir, Reutilizar e Reciclar, mas também inclui os elementos Reimaginar e Reprojetar, no intuito de incrementar a eficiência dos recursos e rever os processos produtivos.

Segundo Adams et al. (2017), diversas definições de Economia Circular têm sido elaboradas, com grande similaridade de princípios e derivadas de um grande número de escolas de pensamento, tal como apresentado no Quadro 1. De acordo com os autores, todos os princípios apresentados partem da mesma premissa: eliminar o conceito de resíduo e maximizar o valor dos materiais (em termos ambientais e econômicos).

Quadro 1 - Princípios da Economia Circular

\begin{tabular}{|l|l|}
\hline \multicolumn{1}{|c|}{ Princípios } & \multicolumn{1}{|c|}{ Fonte } \\
\hline $\begin{array}{l}\text { Proporcionar o incremento de produtividade na utilização de ma- } \\
\text { térias-primas nos processos, ou seja, "fazer mais com menos". }\end{array}$ & $\begin{array}{l}\text { Fuller (1973); Lund (1955); } \\
\text { Stahel (2010). }\end{array}$ \\
\hline $\begin{array}{l}\text { Eliminar o desperdício, permitindo que os resíduos sejam inseridos } \\
\text { nos processos produtivos. }\end{array}$ & $\begin{array}{l}\text { Lyle (1994); McDonough e } \\
\text { Braungart (2002) }\end{array}$ \\
\hline $\begin{array}{l}\text { Manter ou incrementar o valor dos materiais, tanto econômico, } \\
\text { como ambiental. }\end{array}$ & $\begin{array}{l}\text { Weizsacker, Lovins e Lovins } \\
\text { (1997). }\end{array}$ \\
\hline $\begin{array}{l}\text { Pensar nos sistemas produtivos estudando o fluxo de materiais e e } \\
\text { de energia, entendendo os elos entre as diferentes fases, como in- } \\
\text { fluenciam umas às outras e suas consequências; permitindo sem- } \\
\text { pre processos de ciclo fechado nos quais os resíduos servem como } \\
\text { material de "input". }\end{array}$ & $\begin{array}{l}\text { Meadows e ent (1995); } \\
\text { (2008), Pauli (2010). }\end{array}$ \\
\hline
\end{tabular}

Fonte: Adaptados pelos autores a partir de ADAMS et al. (2017)

Segundo Adams et al. (2017), há poucas pesquisas voltadas para o estudo da incorporação do conceito de Economia Circular na construção civil. Na Europa, de acordo com Yuan e Shen (2011), muitas pesquisas têm se focado apenas em soluções tipo "fim de tubo" para manejo dos resíduos. Os aspectos principais do conceito de Economia Circular, aplicados durante o ciclo de vida dos edifícios, obtidos a partir da literatura, são demonstrados no Quadro 2, adaptado de Adams et al. (2017).

Segundo Esa, Halog e Rigamonti (2017b), o Reino Unido e os Países Baixos figuram entre os países que utilizam em suas obras, de forma mais efetiva, práticas baseadas nos conceitos de Economia Circular. Smol et al. (2015) enfatizam que a melhoria dos indicadores de sustentabilidade é essencial para a construção civil, que é um setor mundialmente emergente e uma indústria altamente ativa nos países desenvolvidos e em desenvolvimento. Assim, os autores justificam a necessidade de o setor promover a Economia Circular e novas práticas de desenvolvimento ambiental. 
Quadro 2 - Aspectos de Economia Circular durante o ciclo de vida do edifício

\begin{tabular}{|c|c|}
\hline Estágio do ciclo de vida & Aspectos de Economia Circular \\
\hline \multirow{6}{*}{ Projeto } & Projetar visando à adaptabilidade e flexibilidade \\
\hline & Projetar visando à padronização \\
\hline & Projetar visando à redução de resíduos \\
\hline & Projetar objetivando modularizações \\
\hline & Especificar materiais recuperados \\
\hline & Especificar materiais reciclados \\
\hline \multirow{8}{*}{ Manufatura e suprimentos } & Utilizar conceito de "Eco-Design" \\
\hline & Utilizar menos materiais - otimizar o uso destes \\
\hline & Utilizar menos materiais perigosos (contaminantes) \\
\hline & Utilizar materiais com maior vida útil \\
\hline & Prever a desmontagem do produto \\
\hline & Prever a padronização do produto \\
\hline & Prever sistemas de devolução \\
\hline & Utilizar de logística reversa \\
\hline \multirow{4}{*}{ Construção } & Reduzir a geração de resíduos \\
\hline & Procurar reutilizar materiais \\
\hline & Procurar reciclar materiais \\
\hline & Utilizar peças pré-fabricadas \\
\hline \multirow{5}{*}{ Reformas } & Reduzir geração de resíduos \\
\hline & Reduzir necessidade de manutenção \\
\hline & Utilizar recursos de fácil reparação e substituição \\
\hline & Promover adaptabilidade \\
\hline & Promover flexibilidade \\
\hline \multirow{4}{*}{ Final de ciclo de vida } & Desconstrução \\
\hline & Possibilitar demolição seletiva \\
\hline & Reutilização de componentes \\
\hline & Reciclagem de materiais \\
\hline
\end{tabular}

Fonte: Adaptado pelos autores a partir de ADAMS et al. (2017).

A Economia Circular propõe um caminho factível para o desenvolvimento sustentável, pois sugere um sistema econômico com um ciclo de produção e consumo fechados (GHISELLINI; CIALANI; ULGIATI 2016; SAUVÉ; BERNARD; SLOAN 2016; MURRAY; SKENE; HAYNES 2017). De tal modo, o setor da construção civil, que já exerce influência significativa no desenvolvimento socioeconômico de inúmeros países (SMOL et al., 2015), pode também ser um catalisador para a preservação ambiental a partir de novas práticas de sustentabilidade. Ghisellini, Cialani e Ulgiati (2016) enfatizam que o envolvimento de todos atores em uma cadeia de valor é fundamental para o estabelecimento de uma Economia Circular. O Quadro 3, elaborado a partir de Murray, Skene e Haynes (2017), Ghisellini, Cialani e Ulgiati (2016), Sauvé, Bernard e Sloan (2016), Geissdoerfer et al. (2017) e Preston (2012), apresenta os benefícios gerados pela aplicação dos princípios da Economia Circular na construção civil.

Dessa forma, por meio das informações apresentadas nesta revisão de literatura, é possível identificar a necessidade do setor da construção civil em inserir na gestão de seus resíduos os princípios da Economia Circular, de forma a se obter maior valoração 
dos resíduos gerados, maximizar a utilização de matérias-primas e insumos e reduzir os impactos causados pelo setor no decorrer de suas atividades. A seguir são apresentados os procedimentos metodológicos utilizados nesta pesquisa.

Quadro 3 - Principais benefícios da Economia Circular para a construção civil

\begin{tabular}{|l|l|}
\hline \multicolumn{1}{|c|}{ Autores } & \multicolumn{1}{c|}{ Benefícios da Economia Circular } \\
\hline $\begin{array}{l}\text { Murray, Skene e } \\
\text { Haynes (2017) }\end{array}$ & $\begin{array}{l}\text { Cria um circuito econômico eficiente e fechado, com a baixa utilização de } \\
\text { energia e baixa emissão de poluentes. }\end{array}$ \\
\hline $\begin{array}{l}\text { Ghisellini, Cialani } \\
\text { e Ulgiati (2016) }\end{array}$ & $\begin{array}{l}\text { Promove o uso apropriado e ambientalmente correto dos recursos, visando } \\
\text { à implementação de uma economia mais ecológica e do bem-estar social. }\end{array}$ \\
\hline $\begin{array}{l}\text { Sauvé, Bernard e e } \\
\text { Sloan (2016) }\end{array}$ & $\begin{array}{l}\text { Forma um sistema em que a reutilização e a reciclagem fornecem substitu- } \\
\text { tos para o uso de materiais virgens e recursos naturais, melhorando a capa- } \\
\text { cidade das gerações futuras atenderem suas necessidades. }\end{array}$ \\
\hline $\begin{array}{l}\text { Geissdoerfer et } \\
\text { al. (2017) }\end{array}$ & $\begin{array}{l}\text { Estabelece uma economia regenerativa e de longa duração, em que os flu- } \\
\text { xos de entrada e saída são geridos por um circuito fechado. }\end{array}$ \\
\hline Preston (2012) & $\begin{array}{l}\text { Redução do consumo de matérias-primas e recursos naturais, promovendo } \\
\text { o desenvolvimento sustentável. }\end{array}$ \\
\hline
\end{tabular}

Fonte: Elaborado pelos autores.

\section{PROCEDIMENTOS METODOLÓGICOS}

A metodologia utilizada nesta pesquisa foi o estudo de caso com múltiplas unidades de análise (multicaso ou estudo de casos múltiplos), destacando-se que as usinas selecionadas foram escolhidas pela localidade, porte e modelo de administração (público, privado e misto). Para Yin (2015), o estudo de caso consiste em uma metodologia que abrange planejamento, técnicas de coletas de dados e análise destes. Ainda de acordo com o autor, nessa metodologia pode-se utilizar mais de uma fonte de informação, por exemplo: documentos, registros, entrevistas, observação direta, etc. Também conforme o autor, as unidades de análise são o foco da pesquisa e constituem o caso.

Em relação à análise, esta foi qualitativa, com abordagem exploratória. Conforme Martins e Theóphilo (2009), a pesquisa qualitativa deixa o pesquisador livre para observar, e sua preocupação fica voltada mais para o processo do que para os resultados, possibilitando uma participação mais direta.

Assim, para compor esta pesquisa foi desenvolvido estudo de campo com observação direta, pesquisa a documentos fornecidos pelas UREs e entrevistas com gestores de cada usina. Ao todo, as unidades de análise consistiram em sete Usinas de Reciclagem de Entulho (UREs) que estão instaladas e em funcionamento nos municípios de Jundiaí (1 unid.), Itatiba (1 unid.), Guarulhos (1 unid.), São Paulo (2 unid.), Carapicuíba (1 unid.) e São Bernardo do Campo (1 unid.).

Foram também realizadas entrevistas com um grupo focal composto por cinco engenheiros com experiência em obras civis e de infraestrutura variando entre 15 e 20 anos, a fim de se verificar o conhecimento e aceitação destes em relação à utilização dos agregados reciclados nos serviços de construção, tal como demonstrado no Quadro a seguir. Também foram entrevistados: o presidente da Associação Brasileira para Reciclagem de Resíduos da Construção Civil e Demolição - Abrecon (Gestão 2016-2017) e os gestores das UREs em estudo. Ao todo foram entrevistados 13 indivíduos. Segundo Boni 
e Quaresma (2005), a entrevista com grupos focais consiste em uma coleta de dados com o objetivo de estimular os participantes a discutir acerca de um assunto de interesse comum, ou seja, como um debate aberto acerca do tema. Os moderadores das discussões foram os próprios pesquisadores.

Quadro 4 - Qualificação dos engenheiros entrevistados

\begin{tabular}{|c|l|}
\hline $\begin{array}{c}\text { Engenheiro entre- } \\
\text { vistado }\end{array}$ & \multicolumn{1}{c|}{ Qualificação profissional } \\
\hline E1 & $\begin{array}{l}\text { Profissional que atua buscando e divulgando formas de mitigar impac- } \\
\text { tos ambientais, orientando e atuando junto a UREs }\end{array}$ \\
\hline E2 & $\begin{array}{l}\text { Profissional com largo conhecimento de execução de obras, desde sua } \\
\text { composição à finalização, atuante na parte de orçamentos. }\end{array}$ \\
\hline E3 & $\begin{array}{l}\text { Engenheiro de estruturas com larga experiência em obras de grande } \\
\text { porte de pontes e viadutos. }\end{array}$ \\
\hline E4 & $\begin{array}{l}\text { Profissional experiente em diversos tipos de obras, atuando em pavi- } \\
\text { mentação asfáltica. }\end{array}$ \\
\hline E5 & $\begin{array}{l}\text { Profissional atuante e envolvido no tratamento de RCC, com visão } \\
\text { abrangente e esclarecedora sobre produção e uso de agregados reci- } \\
\text { clados. }\end{array}$ \\
\hline
\end{tabular}

Fonte: Dados da pesquisa.

Para o estudo das respostas fornecidas pelos entrevistados, foi utilizada Metodologia de Análise de Conteúdo. Segundo Campos (2004), esta metodologia se constitui em um conjunto de técnicas utilizadas para análise de dados quantitativos. Para Berelson (1984), a análise de conteúdo visa à descrição do conteúdo manifesto em uma comunicação, de forma clara, objetiva e sistemática. Campos (2004) complementa citando que a análise de conteúdo é orientada por duas fronteiras, ou seja: a fronteira linguística tradicional e a fronteira referente ao território da interpretação do sentido das palavras.

\section{APRESENTAÇÃO E ANÁLISE DE DADOS}

\section{Caracterização das Usinas investigadas}

Em relação à condição de estabelecimento das UREs constatou-se que 3 das 7 pesquisadas atendem a todos os requisitos prescritos na ABNT NBR 15.114/2004 "Resíduos Sólidos da Construção Civil - diretrizes para projeto, implantação e operação", bem como legislações ambientais.

Foi identificado que cinco UREs utilizam somente triagem manual, enquanto o restante utiliza sistema de triagem manual e mecanizada. Tal fato está de acordo com o comentado por John, Ângulo e Kahn (2006), os quais afirmam que a triagem dos RCC nas usinas ocorre predominantemente por métodos manuais, o que reduz a eficiência da operação e permite a ocorrência de contaminante na massa de RCC a ser reciclada.

Quanto ao maquinário instalado, cinco usinas possuem o tipo fixo e duas possuem fixo/móvel. De acordo com Jadovski (2005), os equipamentos móveis podem ser transportados e colocados em funcionamento em outras áreas da usina, quando a quantidade a ser reciclada estiver estocada em local que permita sua operação, sem precisar fazer o transporte do entulho. 
Entre os equipamentos de britagem mais utilizados pelas usinas, o de mandíbula está presente em quatro, enquanto o restante utiliza britador de impacto. Cunha (2007) e Jadovski (2005) comentam que nas usinas brasileiras há a predominância da utilização de britadores do tipo mandíbula, seguido de britadores de impacto. Segundo Lima (1999), o britador de mandíbula é caracterizado pela elevada emissão de ruídos e material particulado.

Também fez parte da caracterização das UREs a verificação dos recursos humanos utilizados na sua operação. No Quadro 5 são demonstrados os dados relativos aos recursos humanos verificados.

Quadro 5 - Recursos humanos das UREs investigadas

\begin{tabular}{|l|c|c|c|c|c|c|c|}
\hline Questões & URE1 & URE2 & URE3 & URE4 & URE5 & URE6 & URE7 \\
\hline Quantidade de funcionários? & ND & 5 & 20 & 22 & 12 & 42 & ND \\
\hline $\begin{array}{l}\text { A equipe possui curso profissiona- } \\
\text { lizante básico, médio, superior ou } \\
\text { nenhum? }\end{array}$ & ND & $\mathrm{N}$ & Médio & $\mathrm{N}$ & $\mathrm{N}$ & $\mathrm{N}$ & $\mathrm{ND}$ \\
\hline $\begin{array}{l}\text { Há algum programa de qualidade } \\
\text { para obtenção dos agregados re- } \\
\text { ciclados? }\end{array}$ & $\mathrm{N}$ & $\mathrm{N}$ & $\mathrm{N}$ & $\mathrm{N}$ & $\mathrm{N}$ & $\mathrm{N}$ & $\mathrm{N}$ \\
\hline $\begin{array}{l}\text { Foi realizado treinamento de se- } \\
\text { gurança? }\end{array}$ & $\mathrm{ND}$ & $\mathrm{N}$ & $\mathrm{S}$ & $\mathrm{N}$ & $\mathrm{N}$ & $\mathrm{S}$ & $\mathrm{S}$ \\
\hline
\end{tabular}

Em que: $N D$ = não informado pela URE; $N=$ não; $S=s i m$.

Fonte: Dados da pesquisa.

Para garantir seu funcionamento as usinas têm quantidades variadas de colaboradores, divididos nas funções de triagem, operação de máquinas, manutenção e controle de produção. As usinas 1 e 7 não declararam quantos colaboradores são empregados nas suas operações. $O$ treinamento em relação a aspectos de segurança dos colaboradores é realizado por apenas três usinas. Em relação à mão de obra, percebe-se que as UREs empregam profissionais com baixo nível de qualificação profissional. Somente a usina 3 declarou possuir funcionários com nível médio de ensino.

Deve-se destacar que a norma ABNT NBR 15.114/2004 recomenda em seu item "7.2.1" que os responsáveis pela URE deverão fornecer treinamento aos colaboradores em relação aos seguintes aspectos: i) forma de operação da reciclagem, com ênfase na atividade específica a ser desenvolvida pelo indivíduo e ii) procedimentos de emergência. Assim, constata-se que nem todas as usinas estão de acordo com o exigido por este item da norma.

Outro aspecto que deve ser destacado consiste na inexistência de programas de qualidade durante produção dos agregados reciclados, ou seja, nenhuma das usinas prospectadas declarou possuir tal ferramenta. A ausência de controle de produção dos agregados conduz à grande variabilidade do material e perda de qualidade, tal como já destacado por John, Ângulo e Kahn (2006).

\section{Entrevistas com Profissionais da Construção Civil, Gestores das UREs e Presidente da Abrecon}

No intuito de se verificar possíveis conflitos e concordâncias entre as opiniões relatadas pelos entrevistados (gestores das URE, engenheiros e presidente da Abrecon), foi elaborada a matriz apresentada no Quadro 6. 
Quadro 6 - Matriz de opiniões elaborada com base nas entrevistas conduzidas

\begin{tabular}{|c|c|c|c|}
\hline \multirow{2}{*}{ Assuntos } & \multicolumn{3}{|c|}{ Entrevistados } \\
\hline & Engenheiros & Abrecon & Gestores das UREs \\
\hline $\begin{array}{c}\text { Utilização dos agre- } \\
\text { gados reciclados nas } \\
\text { obras. }\end{array}$ & $\begin{array}{c}\text { A maioria já utilizou e } \\
\text { não observa problemas } \\
\text { em utilizar agregados } \\
\text { reciclados em suas } \\
\text { obras. }\end{array}$ & $\begin{array}{l}\text { O agregado reciclado ainda } \\
\text { não é largamente difundido e } \\
\text { conhecido na construção civil, } \\
\text { há resistência acerca de sua } \\
\text { qualidade e utilização. }\end{array}$ & $\begin{array}{l}\text { Deve haver mais } \\
\text { divulgação para in- } \\
\text { centivar seu uso. }\end{array}$ \\
\hline $\begin{array}{l}\text { Papel do poder pú- } \\
\text { blico no incentivo à } \\
\text { utilização do agrega- } \\
\text { do reciclado. }\end{array}$ & $\begin{array}{c}\text { Falta incentivo por não } \\
\text { constar em editais, bem } \\
\text { como a obrigatoriedade } \\
\text { de utilização de agrega- } \\
\text { dos reciclados em obras } \\
\text { licitadas. }\end{array}$ & $\begin{array}{l}\text { Os incentivos são mínimos. } \\
\text { Ficam muito mais no campo } \\
\text { da teoria do que prática. Um } \\
\text { avanço importante seria a } \\
\text { isenção do ICMS, por exemplo. }\end{array}$ & $\begin{array}{l}\text { Precisa-se criar leis e } \\
\text { normas incentivando } \\
\text { o uso dos agregados } \\
\text { reciclados, a começar } \\
\text { pelas obras públicas. }\end{array}$ \\
\hline $\begin{array}{c}\text { Papel das usinas na } \\
\text { inserção da variável } \\
\text { ambiental na cons- } \\
\text { trução civil. }\end{array}$ & $\begin{array}{c}\text { Possuem importante } \\
\text { papel, pois, impedem } \\
\text { que os resíduos sejam } \\
\text { depositados em locais } \\
\text { indevidos e ainda redu- } \\
\text { zem a necessidade de } \\
\text { utilização de agregado } \\
\text { natural. }\end{array}$ & $\begin{array}{c}\text { As usinas têm papel impor- } \\
\text { tante, atuam evitando que } \\
\text { os RCC sejam depositados } \\
\text { irregularmente, evitando } \\
\text { contaminar o meio ambiente. } \\
\text { Também reduzem a necessi- } \\
\text { dade de agregados naturais } \\
\text { na construção civil }\end{array}$ & $\begin{array}{l}\text { As usinas têm papel } \\
\text { importante pelo fato } \\
\text { que evitam a depo- } \\
\text { sição irregular dos } \\
\text { resíduos. }\end{array}$ \\
\hline $\begin{array}{l}\text { Aspectos técnicos } \\
\text { acerca da utilização } \\
\text { de agregados reci- } \\
\text { clados nas obras de } \\
\text { construção. }\end{array}$ & $\begin{array}{l}\text { O agregado reciclado } \\
\text { apresenta condições } \\
\text { técnicas necessárias, } \\
\text { quando não há exigên- } \\
\text { cia de resistência estru- } \\
\text { tural, no entanto ainda } \\
\text { há muita heterogenei- } \\
\text { dade e impurezas. }\end{array}$ & $\begin{array}{l}\text { A grande questão está ligada à } \\
\text { impureza dos agregados reci- } \\
\text { clados produzidos. Muitas ve- } \\
\text { zes as usinas não conseguem } \\
\text { triar com eficácia os outros } \\
\text { materiais, como plástico, ma- } \\
\text { deira e ferro, prejudicando a } \\
\text { qualidade do produto. }\end{array}$ & $\begin{array}{l}\text { O agregado reciclado } \\
\text { tem todas as condi- } \\
\text { ções de atender às } \\
\text { exigências das obras, } \\
\text { sendo menos usados } \\
\text { em obras estruturais. }\end{array}$ \\
\hline $\begin{array}{l}\text { Percepção do consu- } \\
\text { midor em relação à } \\
\text { utilização dos agre- } \\
\text { gados reciclados nas } \\
\text { obras. }\end{array}$ & $\begin{array}{l}\text { O agregado reciclado } \\
\text { é pouco consumido } \\
\text { por problema cultural. } \\
\text { Se sua utilização fosse } \\
\text { mais bem divulgada, } \\
\text { esta percepção poderia } \\
\text { ser alterada. }\end{array}$ & $\begin{array}{l}\text { Varia muito, mas, de uma } \\
\text { forma geral, os consumidores } \\
\text { entendem que, por ser reci- } \\
\text { clados, os agregados não têm } \\
\text { qualidade. Dessa forma, os } \\
\text { consumidores têm receio ou } \\
\text { preconceito acerca do uso do } \\
\text { material reciclado. }\end{array}$ & $\begin{array}{c}\text { Por desconhecerem } \\
\text { seu potencial, alguns } \\
\text { veem os agregados } \\
\text { reciclados como algo } \\
\text { que não deve ser } \\
\text { usado. }\end{array}$ \\
\hline $\begin{array}{l}\text { Percepção em re- } \\
\text { lação à vantagem } \\
\text { financeira de utili- } \\
\text { zação do agregado } \\
\text { reciclado em relação } \\
\text { ao agregado natural. }\end{array}$ & $\begin{array}{l}\text { Quando se tem alguma } \\
\text { forma de reciclar na } \\
\text { própria obra ou tem } \\
\text { usina próxima, é mais } \\
\text { vantajoso pela redução } \\
\text { de frete e royalties. }\end{array}$ & $\begin{array}{l}\text { O agregado reciclado tende a } \\
\text { ganhar seu espaço por trazer } \\
\text { redução de custos, algo que } \\
\text { todos buscam em momento } \\
\text { de crise. }\end{array}$ & $\begin{array}{c}\text { Os preços de comer- } \\
\text { cialização dos agre- } \\
\text { gados reciclados são } \\
\text { mais vantajosos em } \\
\text { relação aos naturais, } \\
\text { reduzindo os custos } \\
\text { da obra. }\end{array}$ \\
\hline $\begin{array}{l}\text { Perspectiva acerca } \\
\text { do uso do agregado } \\
\text { reciclado na cons- } \\
\text { trução civil. }\end{array}$ & $\begin{array}{c}\text { Se começassem a } \\
\text { constar em projetos e } \\
\text { editais, existe a possi- } \\
\text { bilidade de melhora no } \\
\text { consumo. }\end{array}$ & $\begin{array}{c}\text { Muitas vezes não é previsto } \\
\text { em edital ou projeto, o que } \\
\text { leva a empreiteira a se sentir } \\
\text { ainda mais insegura a respeito } \\
\text { da aplicação. }\end{array}$ & $\begin{array}{l}\text { Se fosse colocada a } \\
\text { solicitação em edi- } \\
\text { tais, as empresas de } \\
\text { construção civil iriam } \\
\text { aceitar mais fácil. }\end{array}$ \\
\hline
\end{tabular}

Fonte: Dados da pesquisa.

A matriz indica que, entre os entrevistados, há consenso em relação à falta de incentivo de políticas públicas na utilização dos agregados reciclados, o que consiste em um dos fatores limitantes para a difusão da utilização destes insumos nas obras de engenharia. 
Pode-se observar que os engenheiros entrevistados demonstraram boa aceitação quanto à utilização dos agregados reciclados em suas obras, conferindo a este material a importância necessária para a inserção da variável ambiental na construção civil. De acordo com o engenheiro E4: "O uso do material reciclado é muito bom. Já executei obras com estes materiais, uma das obras foi na Avenida Sapopemba (São Paulo), entre o Rodoanel e a Avenida Bento Guelf, totalizando 5,4 km de extensão". Para o engenheiro E2 "a utilização do RCC é muito importante, pois, além de mitigar impacto ambiental, são materiais que poderão ser reaproveitados quantas vezes for preciso".

Os profissionais relataram, no entanto, que a utilização dos agregados reciclados ainda é pequena. Como justificativa, estes destacaram as heterogeneidades e as impurezas encontradas nos agregados produzidos pelas UREs, o que dificulta a aceitação por parte do mercado consumidor. Segundo o engenheiro E1: "O agregado reciclado produzido em pequenas usinas apresenta elevada variabilidade de textura, granulometria e de composição devido ao material-fonte e aos processos de triagem e reciclagem das usinas". De acordo com o presidente da Abrecon, no entanto: "Para funções não estruturais o agregado reciclado, mesmo sendo misto, atende ao propósito."

Deve-se destacar que a necessidade de maior controle de qualidade dos agregados reciclados como fator de influência no incremento da aceitação destes pelo mercado consumidor é citada por autores como Evangelista, Costa e Zanta (2010), John, Ângulo e Kahn (2006), Cunha (2007), Vieira; Dal Molin e Lima (2004).

Neste contexto, os gestores das usinas e o presidente da Abrecon ressaltam a necessidade de instalação de sistemas de qualidade e normatização nas UREs, no intuito de possibilitar a produção de agregados mais homogêneos e com melhores características.

Ainda há, no entanto, um longo caminho a percorrer, uma vez que, para algumas usinas, ainda faltam adequações de local, equipamento e treinamento de pessoal. Tal situação pôde ser constatada nesta pesquisa no Quadro 5, observando-se que as usinas prospectadas não dispõem de ferramentas de controle de qualidade dos agregados produzidos. Ademais, também se constatou que as usinas empregam funcionários com baixa qualificação profissional.

O presidente da Abrecon destaca a dificuldade das usinas em realizar a triagem dos resíduos de construção recebidos, o que resulta em impurezas nos volumes finais de agregados reciclados. Para ele "a grande questão está ligada à impureza. Muitas vezes as usinas não conseguem triar com eficácia os outros materiais como: plástico, madeira e ferro, prejudicando a qualidade do produto."

Esta situação foi verificada neste estudo durante a caracterização das UREs. Os resultados demonstraram que a maioria das usinas dispõe apenas de triagem manual, que, por ser realizada sem ajuda de equipamentos mecânicos, apresenta menor eficiência, permitindo muitas vezes a ocorrência de materiais contaminantes nas pilhas de resíduos, ou seja, materiais não classificados como Classe A pela resolução Conama $n^{\circ} 307 / 2002$. Cunha (2007) e John, Ângulo e Kahn (2006) comentam que a maioria das UREs no país ainda realizam triagem manual e visual dos resíduos, o que colabora para uma baixa qualidade final dos agregados produzidos. Vieira, Dal Molin e Lima (2004), 
Evangelista, Costa e Zanta (2010) comentam que, quando adotadas ferramentas de controle de produção dos agregados reciclados é possível ampliar o seu emprego, além de proporcionar ganhos ambientais e econômicos para a obra.

Na visão dos entrevistados, a baixa utilização dos agregados reciclados nas obras também está relacionada à falta de conhecimento do mercado consumidor. Segundo estes, há a ideia de que, pelo fato de o agregado ser reciclado, este não possui qualidade necessária para a obra. Segundo o presidente da Abrecon: "O agregado reciclado ainda não é largamente difundido e conhecido na construção civil. Ainda há resistência sobre a sua qualidade e aplicação". Para o gestor da URE2: "O material seria melhor aceito se houvesse um trabalho de divulgação para que as pessoas tivessem conhecimento da aplicabilidade do RCC, isso iria mudar a cultura adotada de que só o material natural tem valor". Na visão do engenheiro E4, “...os órgãos púbicos não utilizam e os projetistas não recomendam em seus projetos. Por falta de conhecimento técnico dos materiais e que não temos literatura sobre ele no Brasil".

Dessa forma, os entrevistados destacam o preconceito da utilização deste insumo, mesmo apresentando preços de comercialização inferiores aos agregados naturais. Para os gestores das UREs, a criação e atualização de normas técnicas e incentivos governamentais poderiam ajudar a reverter esta situação. Neste contexto o gestor da URE6 destaca: "Reciclar exige compromisso com o meio ambiente, mas falta estímulo do poder público para se expandir e também tornar o processo mais barato, bem como divulgação da qualidade do material, para que o mercado tenha melhor aceitação do reciclado". Acerca do apoio governamental o presidente da Abrecon comenta: "Os incentivos do poder público são mínimos. Ficam muito mais no campo da teoria do que da prática. Um avanço importante seria a isenção do ICMS, por exemplo". O engenheiro E4 sugere que: "O governo teria que fazer uma lei de âmbito nacional obrigando a usar um percentual em suas obras, onde diminuiria os descartes deste material em bota-fora, hoje em virtude da economia o material virgem está com o mesmo preço, ou quase igual ao reciclado".

Os gestores destacam que, se as obras públicas começassem a dar preferência ao agregado reciclado, possivelmente isso serviria de estímulo ao setor privado. Como constatado, somente as usinas públicas e aquelas geridas por meio de modelo de parceria público-privada é que fornecem agregados reciclados para as prefeituras dos municípios onde estas se localizam; contudo, os gestores destas usinas reclamam que os volumes destinados para as prefeituras ainda são modestos.

Em relação ao papel ambiental das usinas de reciclagem de entulho, os entrevistados concordam com Manfrenato, Esguícero e Martins (2008), Paschoalin Filho, Duarte e Faria (2016) e Souza, Segantini e Pereira (2008), em relação às UREs desempenharem fundamental importância na inserção da sustentabilidade no setor da construção civil. Entre as vantagens ambientais citadas destacam-se a redução da necessidade de extração de agregados naturais e a mitigação do descarte irregular dos RCC. Para o gestor da URE 3: "Para o gestor da planta, o uso de agregados reciclados tem beneficiado o meio ambiente evitando a retirada de agregados do meio natural e também na economia em obras com a deposição de resíduos produzidos nos processos. Creio que falta incentivo do governo para tornar o produto competitivo". O engenheiro E3 comenta que: "Em razão da dificuldade de descarte de materiais de obra, o RCC torna-se uma opção que 
além de econômica é ecologicamente correta". Segundo o presidente da Abrecon: "O beneficiamento desses resíduos acaba sendo extremamente importante tanto para 0 âmbito ambiental em que se aliviam os impactos ocasionados pelo mesmo ao meio ambiente, assim como em caráter econômico".

Os entrevistados também apontam vantagens financeiras na utilização dos agregados reciclados. Segundo estes, a reciclagem proporciona valoração de resíduos que seriam simplesmente descartados. Ademais, segundo estes, os preços de comercialização dos agregados reciclados são bem menores quando comparados aos dos agregados naturais. Tal fato já foi abordado por Stevenato (2005), Miranda, Ângulo e Careli (2009) e Paschoalin Filho, Duarte e Faria (2016).

Os engenheiros também destacaram a vantagem financeira em relação à redução dos valores de frete, uma vez que as UREs costumam estar situadas mais próximas do mercado consumidor do que as pedreiras e jazidas. Segundo os engenheiros, a reciclagem "in loco" nas obras por meio de usinas móveis pode reduzir ainda mais os custos com o frete. Também salientam que a reciclagem dos resíduos de construção possibilita a redução de custos com os royalties cobrados pelas áreas licenciadas de "bota-fora", o que encarece significativamente os custos de destinação final desses resíduos. Dessa forma, o panorama geral e as barreiras enfrentadas na utilização dos agregados reciclados, levantados por meio das entrevistas conduzidas, encontram-se aderentes ao já relatado por Silva, Brito e Dhir (2017), como se verifica na Figura 1.

Figura 1 - Principais barreiras que impedem maior utilização dos agregados reciclados nas obras

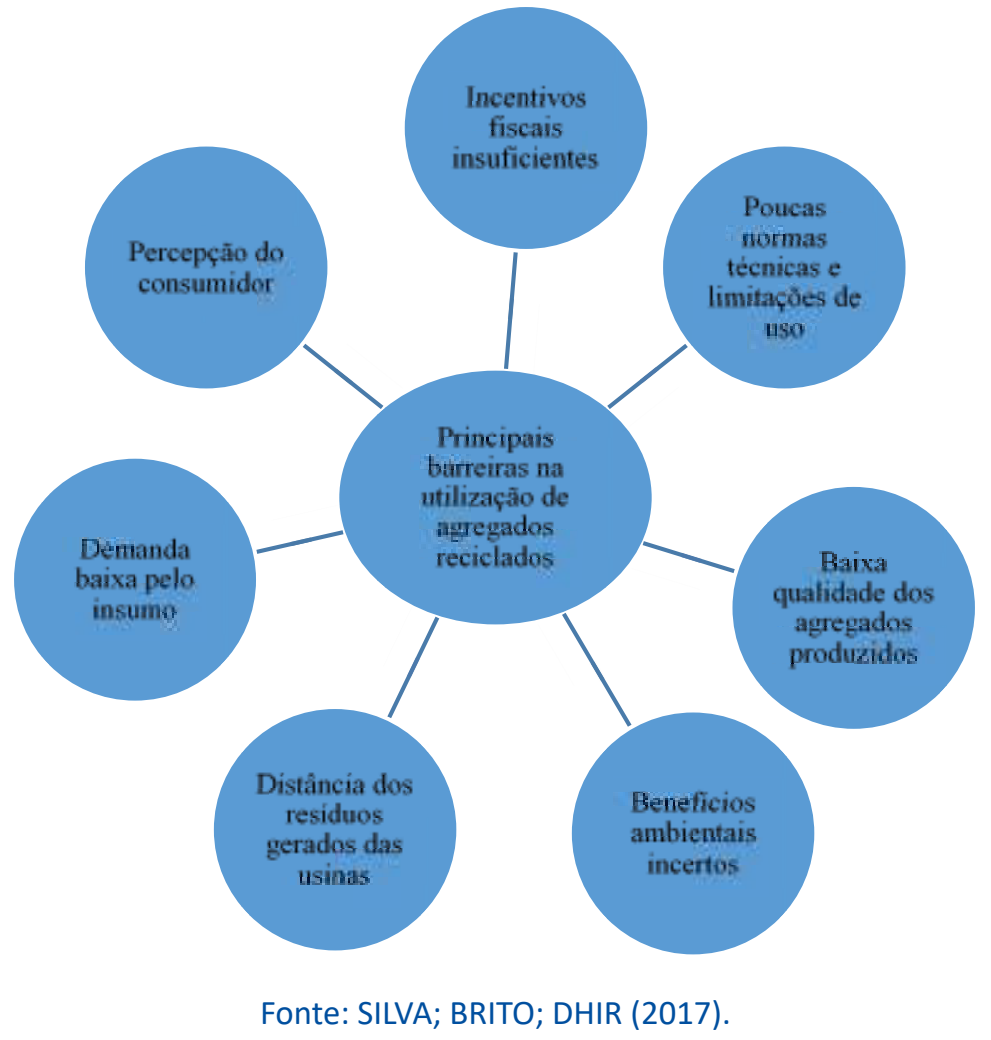

Mesmo com as dificuldades de inserção dos agregados reciclados nas obras, todos os entrevistados acreditam no potencial de utilização deste material. Segundo eles, a maior utilização dos agregados produzidos pelas UREs ocorrerá quando o mercado 
dispuser de informações mais consistentes em relação ao material e quando houver maiores incentivos governamentais, tais como legislações específicas prevendo a obrigatoriedade de utilização de agregados reciclados nas obras e incentivos fiscais, opinião que concorda com o apresentado por Evangelista, Costa e Zanta (2010). Para o presidente da Abrecon: "As expectativas a curto e médio prazo para a construção civil não são boas. Mas o agregado tende a ganhar seu espaço por trazer redução de custos, algo que todos buscam em momento de crise". O gestor da URE 2 cita: "As barreiras são naturais e estão sendo superadas dia a dia. O produto ainda é novo e entendemos que cada vez mais ele será difundido e se tornará mais comum nos canteiros de obras".

\section{Usinas de Reciclagem de Entulho e a Economia Circular}

Os entrevistados destacam que o agregado reciclado reduz os danos causados ao meio ambiente pelo setor da construção e que os benefícios deste processo podem ser ainda maiores, tal como já exposto por Ghisellini, Cialani e Ulgiati (2016).

A reciclagem do entulho pelas UREs possibilita a reinserção do RCC nas obras, reduzindo não só a deposição irregular do material, mas também a necessidade de extração de matérias-primas naturais. Tal aspecto pode ser relacionado a Preston (2012) e Geissdoerfer et al. (2017), os quais comentam que os benefícios da Economia Circular estão relacionados à redução do consumo de matérias-primas e à reinserção dos resíduos nos ciclos produtivos. As UREs permitem a geração de novos empregos e o fomento de um novo mercado, auxiliando na promoção do desenvolvimento socioeconômico do setor da construção. Assim como a sustentabilidade, a Economia Circular deve estabelecer o equilíbrio entre as dimensões social, econômica e ambiental (PRESTON, 2012; GHISELLINI; CIALANI; ULGIATI 2016). De tal modo, a reciclagem de entulho nas UREs gera ações para o crescimento econômico, a inclusão social (por meio do emprego de mão de obra) e a preservação da natureza, uma vez que reduz a necessidade de exploração de recursos naturais.

Em relação ao mercado, os entrevistados acreditam que a perspectiva de uso do RCC ainda seja tímida diante das barreiras impostas para a utilização do agregado reciclado, já citadas por Silva, Brito e Dhir (2017). Foi ressaltado, contudo, que ações de incentivo e divulgação quanto à qualidade e aplicabilidade do RCC possam conferir ao agregado reciclado maior aceitação, gerando aumento de consumo pelo setor da construção civil.

Em um primeiro momento, o trabalho que uma URE realiza pode parecer somente o compromisso de receber resíduos de obras e reciclá-los. As UREs, porém, configuram-se como um instrumento de Economia Circular (PRESTON, 2012). Além disso, elas também se destacam ao produzir indicadores ambientais positivos quando se trata de consumo e controle de agregados para a construção civil. Ressalta-se que indicadores ambientais são fundamentais para compreender e avaliar uma realidade, o que facilita a criação de processos cada vez mais eficientes dentro dos princípios da Economia Circular, tal como comentado por Smol et al. (2015). Nesse contexto, o modelo apresentado na Figura 2 é fundamentada nos princípios da Economia Circular, tal como descrito por Murray, Skene e Haynes (2017), Ghisellini, Cialani e Ulgiati (2016), Sauvé, Bernard e Sloan (2016) e Geissdoerfer et al. (2017). 


\section{Figura 2 - Economia Circular de RCC em uma obra com a presença das UREs}

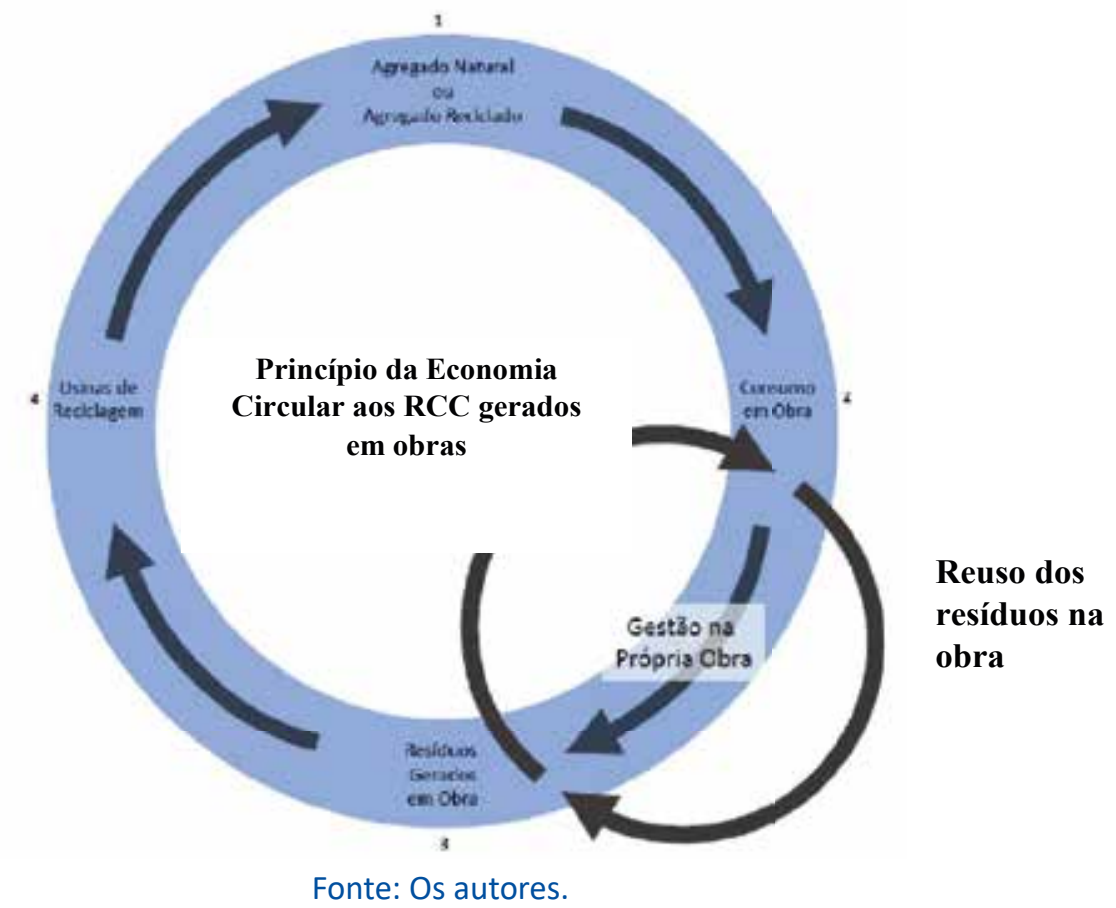

O modelo apresentado na Figura 2, baseado no conceito de Economia Circular, demonstra as várias etapas do ciclo produtivo de uma obra, que se inicia na extração dos agregados na natureza, passando pelo consumo destes nas obras e sua destinação. Nota-se que as UREs produzem, por meio da reciclagem dos resíduos, agregados que podem ser reinseridos na cadeia da construção civil, possibilitando o fechamento do ciclo produtivo e tornando possível a alteração do sistema linear tradicional da cadeia produtiva da obra para um formato circular.

Esa, Halog e Rigamonti (2017a) destacam que a fase executiva de uma obra é a que mais contribui para a geração de resíduos e, diante disso, a alteração do sistema linear (extrair-produzir-consumir-descartar) para o circular é necessária para se atingir o desenvolvimento ambientalmente sustentável do setor da construção. A Figura 2, portanto, promove uma reflexão em relação ao fluxo de materiais em uma obra sob forma de um ciclo fechado, na qual os resíduos servem como material de "input" na obra, tal como comentado por Graedel e Allenby (1995), Meadows e Wright (2008) e Pauli (2010).

Ressalta-se que a reciclagem dos RCC, por meio das UREs, proporciona o incremento de produtividade referente à utilização das matérias-primas naturais nas obras, além de valoração e máxima utilização do resíduo gerado, agregando valor financeiro a um material que seria descartado. A valoração dos resíduos e a eficiência na utilização das matérias-primas também consistem em ações ligadas aos princípios da Economia Circular, tal como comentam Lyle (1994), McDonough e Braungart (2002), Fuller (1973), Lund (1955) e Stahel (2010).

Diante deste contexto, as UREs têm o potencial de desempenhar importante papel na inserção dos princípios da Economia Circular na construção civil, uma vez que consistem em uma importante etapa de fechamento de um ciclo que produz-utiliza-gera resíduos-recicla-reinsere os resíduos (já reciclados) na cadeia produtiva. Os be- 
nefícios obtidos por meio da inserção dos princípios da Economia Circular são descritos por Murray, Skene e Haynes (2017), Ghisellini, Cialani e Ulgiati (2016), Sauvé, Bernard e Sloan (2016) Geissdoerfer et al. (2017) e Preston (2012).

No entanto, apesar das URE apresentarem potencial como ferramentas de inserção dos princípios da Economia Circular na Construção Civil, os estudos de caso realizados nas usinas prospectadas demonstraram que tal fato ainda pode estar relativamente distante de ocorrer.

Constatou-se que a maior parte das usinas ainda carece de equipamentos mais eficientes para produção dos agregados reciclados. Tal situação, aliada a baixa qualificação dos funcionários das URE e a falta de programas de qualidade da produção, conduzem a um produto heterogêneo que, mesmo sendo mais barato que o agregado natural, ainda enfrenta resistência do mercado consumidor. Assim, pode-se dizer que as URE ainda apresentam carências técnicas e limitações operativas.

Os entrevistados acreditam na necessidade de implantação de um programa de qualidade nas usinas de uma forma geral. Tal iniciativa certamente poderia contribuir de forma efetiva no incremento da qualidade dos agregados reciclados e na sua aceitação por parte do mercado. Contudo, os entrevistados, não comentaram como este programa poderia ser realizado. Ghisellini, Cialani e Ulgiati (2016) destacam que a Economia Circular implica na adoção de padrões de produção mais limpos e de maior qualidade para as empresas, além de aumento de responsabilidade e de conscientização dos produtores e consumidores, sendo necessária a colaboração entre todas as partes envolvidas.

\section{CONCLUSÕES E RECOMENDAÇÕES}

No momento em que as URE promovem a reciclagem dos RCC, coloca-se em prática os princípios de Economia Circular, ou seja, os resíduos gerados pelas atividades de construção são reinseridos no ciclo produtivo, reduzindo a necessidade de extração de matérias-primas naturais e danos ambientais decorrentes. Conforme Sauvé, Bernard e Sloan (2016) e Geissdoerfer et al. (2017), isso significa que a energia e os recursos primários utilizados para a produção dos materiais retornam ao seu ciclo de vida.

A pesquisa realizada indica que, apesar de as Usinas de Reciclagem de Entulho serem importantes na promoção da Economia Circular, apresentam limitações nas operações e processos, o que prejudica a aceitação, do mercado consumidor, do agregado reciclado produzido, mesmo este apresentando custo de aquisição inferior ao agregado tradicional (natural).

As limitações estão relacionadas à falta de infraestrutura logística, à utilização de sistemas manuais e à baixa de qualificação técnica dos profissionais envolvidos no processo. Além disso, a pesquisa identificou que a baixa demanda do mercado pelos agregados produzidos pelas UREs está associada à percepção do consumidor acerca da qualidade irregular dos produtos, a qual precisa ser melhorada por meio da criação de programas de qualidade. 
O estudo indica ainda que ações como a divulgação dos benefícios financeiros e ambientais dos materiais reciclados, bem como a criação de incentivos fiscais e de mecanismos regulatórios poderiam auxiliar a alavancar o mercado de agregado reciclado e a disseminação das UREs no Brasil. Trata-se de uma ação necessária para a mudança de cultura do setor.

A construção civil influencia de forma positiva o desenvolvimento socioeconômico do país por meio da sua contribuição para o crescimento do Produto Interno Bruto (PIB), na geração de empregos e na criação de infraestrutura, no entanto, uma significativa parcela das construtoras brasileiras ainda trabalha sua cadeia produtiva de forma linear. Isso significa que a cadeia de valor do setor deve adotar práticas de Economia Circular para reduzir o consumo de recursos naturais e de matérias-primas, além de criar um ciclo inteligente para a reutilização dos resíduos gerados em suas operações, evitando o seu descarte inapropriado e outras práticas insustentáveis, tal como apresentado no modelo proposto nesta pesquisa.

Este artigo recomenda que pesquisas futuras sejam realizadas para compreender e estruturar caminhos para a incorporação do conceito de Economia Circular no setor da construção civil no Brasil, pois esse mercado é um dos principais responsáveis pelo desenvolvimento do país e pode ser um indutor para a criação de uma economia mais ecológica e socialmente responsável.

Conclui-se, portanto, que o desenvolvimento do conceito de Economia Circular na cadeia de valor da construção civil passa pelo envolvimento de todos os atores do setor, os quais devem se engajar e criar, de forma colaborativa, uma solução integrada para as suas operações.

\section{REFERÊNCIAS}

ABNT. Associação Brasileira de Normas Técnicas. ABNT: NBR 15.114: 2004. Resíduos da Construção Civil Áreas de reciclagem - Diretrizes para o projeto, implantação e operação. Rio de Janeiro, 2004.

ABRECON. Associação Brasileira para Reciclagem de Resíduos da Construção Civil e Demolição. Panorama das usinas de reciclagem de RCD no Brasil: a pesquisa setorial Abrecon 2014/2015. São Paulo, SP: Abrecon, 2016.

ADAMS, K. T.; OSMANI, M.; THORPE, T.; THORNBACK, J. Circular Economy in construction: current awareness, challenges and enablers. Waste and Resource Management, v. 170, p. 15-24, 2017. Available from: https://doi.org/10.1680/jwarm.16.00011.

ARIF, M.; BENDI, B.; TOMA-SABBAGH, T. Construction waste management in India: an exploratory study. Construction Innovation, n. 12, v. 2, p. 133-155, 2012.

AZEVEDO, G.; KIPERSTOK, A. Resíduos da construção civil em Salvador: os caminhos para uma gestão sustentável. Engenharia Sanitária Ambiental, n. 2, v. 1, p. 65-72, 2006.

BARROS, E.; JORGE, F. C. Gestão de RCD Resíduos de Construção e Demolição, na Obra de Ampliação do Aeroporto Francisco Sá Carneiro. Revista da Faculdade de Ciência e Tecnologia, Porto, n. 5, p. 62-74, 2008. BERELSON, B. Content analysis in communication research. New York: Hafner, 1984.

BONI, V.; QUARESMA, S. J. Aprendendo a entrevistar: como fazer entrevistas em ciências sociais. Revista Eletrônica de Pós-Graduandos em Sociologia e Política da UFSC, n. 3, v. 2, p. 68-80, 2005.

BODI, J.; BRITO FILHO, J. A.; ALMEIDA, S. Utilização de entulho de construção civil reciclado na pavimentação urbana. In: REUNIÃO ANUAL DE PAVIMENTAÇÃO, 29., ABPV, 1995, Cuiabá. Anais [...]. Cuiabá, MT, 1995. p. 409-436. V. 3.

CAMPOS, C. J. G. Método de análise de conteúdo: ferramenta para análise de dados qualitativos no campo da saúde. Revista Brasileira de Enfermagem, Brasília, n. 57, v. 5, p. 611-614, 2004.

CUNHA, N. A. Resíduos da construção civil: análise de usinas de reciclagem. 2007. 176p. Dissertação (Mestrado) - Universidade Estadual de Campinas, Faculdade de Engenharia Civil, Arquitetura e Urbanismo, 2007. 
CÂMARA BRASILEIRA DA INDÚSTRIA DA CONSTRUÇÃO CIVIL. Banco de dados, 2016. Disponível em: http://.cbicdados.com.br/institucional. Acesso em: 19 set. 2017.

CONAMA. Conselho Nacional do Meio Ambiente. Resolução no 307, de 5 de julho de 2002. Estabelece diretrizes, critérios e procedimentos para a gestão dos resíduos da Construção Civil. Diário Oficial da União, Brasília, DF. Disponível em: http:// www.mma.gov.br/port/conama/-index.cfm.

DIAS, J. A construção civil e o meio ambiente. In: CONGRESSO ESTADUAL DE PROFISSIONAIS CREA, 2004, Minas Gerais. Anais [...]. Uberlândia, Minas Gerais, 2004.

ELLEN MACARTHUR FOUNDATION. Uma economia circular no Brasil: uma abordagem exploratória inicial, 2017. Disponível em: http://www.elenmacarthurfoundation.org/. Acesso em: 6 mar. 2017.

ESA, M. R.; HALOG, A.; RIGAMONTI, L. Strategies for minimizing construction and demolition wastes in Malasya. Resources, Conservation and Recycling, v. 120, p. 219-229, 2017a. Available from: https://doi. org/10.1016/j.resconrec. Cited: Dec. 2016.

ESA, M. R.; HALOG, A.; RIGAMONTI, L. Developing strategies for managing construction and demolition wastes in Malasya based on concept of circular economy. Journal of Material Cycles and Waste Management, n. 19, v. 3, p. 1.144-1.154, 2017b. DOI: 10.1007/s10163-016-0516-x.

EVANGELISTA, P. P. A.; COSTA, D. B.; ZANTA, M. V. Alternativa sustentável para destinação de resíduos de construção Classe A: sistemática para reciclagem em canteiros de obras. Revista Ambiente Construído, Porto Alegre, n. 10, v. 3, p. 23-40, 2010.

FULLER, B. R. Nine Chairs to the Moon: An Adventure Story of Thought. London U.K.: Jonathan Cape, 1973.

GEISSDOERFER, M.; SAVAGET, P.; BOCKEN, N. M.; HULTINK, E. J. The Circular Economy - A new sustainability paradigm? Journal of Cleaner Production, n. 143, p. 757-768, 2017.

GHISELLINI, P.; CIALANI, C.; ULGIATI, S. A review on circular economy: the expected transition to a balanced interplay of environmental and economic systems. Journal of Cleaner Production, n. 114, p. 11-32, 2016.

GOMES, C. F.; NUNES, K. R.; XAVIER, L. H.; CARDOSO, R.; VALLE, R. Multicriteria decision making applied to waste recycling in Brazil. Omega, n. 36, v. 3, p. 395-404, 2008.

GRAEDEL, T.; ALLENBY, B. Industrial Ecology. NJ, USA: Englewood Cliffs; Prentice Hall, 1995.

HWANG, B. G.; YEO, Z. B. Perception on benefits of construction waste management in the Singapore construction industry. Engineering, Construction and Architectural Management, n. 18, v. 4, p. 394-406, 2011.

INGLEZAKIS, V. J.; ZORPAS, A. Industrial hazardous waste in the framework of EU and international legislation. Management of Environmental Quality, n. 22, v. 5, p. 566-580, 2011.

JADOVSKI, I. Diretrizes técnicas e econômicas para usinas de reciclagem de resíduos de construção e demolição. 2005. 180p. Dissertação (Mestrado) - Universidade Federal do Rio Grande do Sul, Porto Alegre, 2005.

JOHN, V. M. Reciclagem de resíduos na construção civil: contribuição à metodologia de pesquisa e desenvolvimento. 2000. Tese (Livre Docência). Escola Politécnica da Universidade de São Paulo, São Paulo, 2000.

JOHN, V. M.; ÂNGULO, S. C.; KAHN, H. Controle de qualidade dos agregados de resíduos de construção e demolição reciclados para concretos a partir de uma ferramenta de caracterização. Coletânea Habitare, n. 7, p. 168-207, 2006.

KARPINSKI, L.; MICHEL, P.; MACULAN, L.; GUIMARÃES, J.; SAÚGO, A. Proposta de gestão de resíduos da construção civil par o município de Passo Fundo - RS. In: ENCONTRO NACIONAL DE ENGENHARIA DE PRODUÇÃO, 28., 2008, Rio de Janeiro. Anais [...]. Rio de Janeiro: Abepro, 2008. p. 2-15.

LEAL, A. I. G. C. O impacto da economia circular na cadeia de valor: o contexto das empresas Portuguesas. 2015. Dissertação (Mestrado) - Universidade do Minho, Braga, Portugal, 2015.

LEITÃO, A. Economia circular: uma nova filosofia de gestão para o século XXI. Portuguese Journal of Finance, Management and Accounting, Porto: UCP, n. 2, p. 149-171, 2015.

LEVY, S. M.; HELENE, P. R. L. Evolução histórica da utilização do concreto como material de construção. Boletim Técnico da Escola Politécnica - USP. São Paulo, 2002.

LIMA, J. A. R. Proposição de diretrizes para produção e normatização de resíduos de construção reciclado e de suas aplicações em argamassa e concreto. 1999. Dissertação (Mestrado) - USP, São Carlos, 1999.

LU, W.; YUAN, V. W. Y. Construction waste management policies and their effectiveness in Hong Kong: A longitudinal review. Renewable and Sustainable Energy Reviews, n. 23, v. 16, p. 214-223, 2011. 
LUND, R. T. Making Products Live Longer: a Paper for the Environment Directorate of the Organization of Economic Cooperation and Development. Cambridge, MA, USA: Massachusetts Institute of Technology, 1955.

LYLE, J. Regenerative Design for Suistanable Development. New York, NY, USA: John Wiley, 1994.

MANFRENATO, J. W. S.; ESGUÍCERO, F. J.; MARTINS, B. L. Implementação de usina para reciclagem de resíduos da construção civil como ação para o desenvolvimento sustentável-estudo de caso. In: ENCONTRO NACIONAL DE ENGENHARIA DE PRODUÇÃO, Rio de Janeiro. Anais [...]. Rio de Janeiro, 2008.

MARTINS, G. A.; THEÓPHILO, C. R. Metodologia da investigação científica para ciências sociais aplicadas. 2. ed. São Paulo. Ed. Atlas, 2009.

McDONOUGH, W.; BRAUngART, M. Cradle to Cradle. New York, NY, USA: North Point Press, 2002.

MEADOWS, D.; WRIGHT, D. Thinking in Systens - A Primer. VT, USA: Chelsea Green Publishing; White River Junction, 2008.

MELO, A.V. S. Diretrizes para a produção de agregado reciclado em usinas de reciclagem de resíduos da construção civil. 2011. Dissertação (Mestrado) - Universidade Federal da Bahia, Salvador, 2011.

MELO, A. V. S.; FERREIRA, E. A. M.; COSTA, D. B. Fatores críticos para a produção de agregado reciclado em usinas de reciclagem de RCC da região Nordeste do Brasil. Revista Ambiente Construído, n. 13, v. 3, p. 99-115, 2013.

MIRANDA, L. F. R.; ANGULO, S.; CARELI, E. A reciclagem de resíduos de construção e demolição no Brasil: 1986-2008. Ambiente Construído, Porto Alegre, n. 9, v. 1, p. 57-71, 2009.

MURRAY, A.; SKENE, K.; HAYNES, K. The circular economy: an interdisciplinary exploration of the concept and application in a global context. Journal of Business Ethics, n. 140, v. 3, p. 369-380, 2017.

OYEDETE, L. O.; REGAN, M.; MEDING, J.; AHMED, A.; OBAS, J.; ELNOKALY, A. Reducting waste to lanfill in the UK: identifying impediments and critical solutions. World Journal of Science, Technology and Sustainable Development, n. 10, v. 2, p. 131-142, 2013.

PAULI, G. The Blue Economy: 10 Years - 100 Innovations - 100 Million. Report to the Club of Rome. Taos, NM, USA: Paradigm Publications, 2010.

PASCHOALIN FILHO, J.; DUARTE, E.; FARIA, A. Geração e manejo dos resíduos de construção civil nas obras de edifício comercial na cidade de São Paulo. Espacios, n. 37, v. 6, p. 30-45, 2016.

PASCHOALIN FILHO, J.; STOROPOLI, J.; DUARTE, E. Viabilidade econômica da utilização de resíduos de demolição reciclados na execução do contrapiso de um edifício localizado na Zona Leste da cidade de São Paulo. REGET, UFSM, n. 18, v. 2, p. 928-943, 2014.

PASCHOALIN FILHO, J. A; DUARTE, E. B.; GUERNER DIAS, A. J.; CORTES, P. L. Manejo de resíduos de demolição gerados durante as obras da arena de futebol Palestra Itália (Allianz Parque) localizada na cidade de São Paulo/Brasil. Revista Holos, n. 6, v. 3, p. 73-91, 2013.

PRESTON, F. A global redesign? Shaping the circular economy. Energy, environment and resource governance. London: Chatham House, 2012.

SAUVÉ, S.; BERNARD, S.; SLOAN, P. Environmental sciences, sustainable development and circular economy: Alternative concepts for trans-disciplinary research. Environmental Development, n. 17, p. 48-56, 2016.

SILVA, R. V.; BRITO, J. de; DHIR, R. K. Availability and processing of recycled aggregates within the construction and demolition supply chain: A review. Journal of Cleaner Production, n. 143, p. 598-614, 2017. https://doi.org/10.1016/j.jclepro.2016.12.070.

SMOL, M.; KULCZYCKA, J.; HENCLIK, A.; GORAZDA, K.; WZOREK, Z. The possible use of sewage sludge ash (SSA) in the construction industry as a way towards a circular economy. Journal of Cleaner Production, n. 95, p. 45-54, 2015.

SOUZA, M. I. B.; SEGANTINI, A. A. S.; PEREIRA, J. A. Tijolos prensados de solo-cimento confeccionados com resíduos de concreto. Revista Brasileira de Engenharia Agrícola e Ambiental, n. 12, v. 2, p. 2.0152.212, 2008.

SCHNEIDER, D.; PHILIPPI JR. A. Gestão pública de resíduos da construção civil no município de São Paulo. Ambiente Construído, n. 4, v. 4, p. 21-32, 2004.

STEVENATO, S. Estudo da viabilidade de implantação de usina de moagem de entulho com recursos da iniciativa privada no município de Bauru/SP. 2005. 137p. Dissertação (Mestrado em Engenharia Mecânica) - Faculdade de Engenharia, Universidade Estadual Paulista, 2005.

STAHEL, W. R. The Performance Economy. Basingstoke, U.K.: Palgrave Macmillan, 2010.

ULSEN, C.; KAHN, H.; ANGULO, S.; JOHN, V. Composição química de agregados mistos de resíduos de construção e demolição do estado de São Paulo. Revista da Escola de Minas, Ouro Preto, n. 63, v. 2, p. 339-346, 2010. 
VIEIRA, G. L.; DAL MOLIN, D. C. C.; LIMA, F. B. de. Resistência e durabilidade de concreto produzidos com agregados reciclados provenientes de resíduos de construção e demolição. Engenharia Civil, n. 1, v. 19, p. 5-18, 2004.

WEIZSÄCKER, E. U. von; LOVINS, A. B.; LOVINS, L. H. Factor Four: Doubling Wealth - halving Resource Use. London: Earthscan, 1997.

YIN, R. K. Estudo de caso: planejamento e métodos. 5. ed. Porto Alegre: Ed. Bookman, 2015.

YUAN, H. A model for evaluating the social performance of construction waste management. Waste Management, n. 32, v. 6, p. 1.218-1.228, 2012.

YUAN, H.; SHEN, L. Trend of the research on construction and demolition waste management. Waste Management, n. 31, v. 4, p. 670-679, 2011.

TAM, V. W.; KOTRAYOTHAR, D.; LOO, Y. C. On the prevailing construction waste recycling practices: a South East Queensland Study. Waste Management and Research, v. 27, p. 167-174, 2009. 